\title{
Scaling Evaluation of Ice-Crystal Icing on a Modern Turbofan Engine in PSL Using the COMDES-MELT Code
}

\author{
Jen-Ching Tsao \\ Ohio Aerospace Institute
}

\begin{abstract}
This paper presents preliminary ice-crystal icing (ICI) altitude scaling evaluation results of a Honeywell Uncertified Research Engine (HURE) that was tested in the NASA Glenn Research Center Propulsion Systems Laboratory (PSL) during January of 2018. This engine geometry features a hidden core design to keep the core less exposed. The engine was fitted with internal video cameras to observe various ice buildup processes at multiple selected locations within the engine core flow path covering the fan stator, the splitter$\mathrm{lip} /$ shroud/strut, and the high pressure compressor (HPC) variable inlet guide vane (IGV) regions. The potential ice accretion risk was pre-determined to occur by using NASA's in-house 1D Engine Icing Risk assessment code, COMDES-MELT. The code was successful in predicting the risk of ice accretion in adiabatic regions like the fanstator of the HURE at specific engine operating points. However at several operating points during the test, liquid water was observed running along the shroud toward the variable IGV of the HPC regions with an air temperature well below freezing, thus no particle melting could have occurred due to heating from the air alone. It was reasoned that other sources of heat were present in that region. To account for these heat sources the inlet total temperature was adjusted to give a wet bulb temperature of $24^{\circ} \mathrm{F}$ below the standard minimum wet bulb temperature of $492{ }^{\circ} \mathrm{R}$ to allow ice to accrete in the splitterlip/shroud/strut region, which was determined from a reference case where hard ice was observed in that region. With that adjustment the COMDES-MELT code was successful in providing operating points where there was a risk of ice accretion during the test campaign. In addition to calculating possible conditions at different selected lower altitudes, simulations were run to determine potential inlet conditions that could lead to ice-crystal accretion along the prescribed stations where the cameras were available. From there, scaled test conditions were determined by best matching the following three icing related parameters of the reference condition: (1) the local air total wet bulb temperature, (2) the local ice crystal cloud melt ratio and (3) the engine fan face ice/water to air mass flux ratio of the ice crystal cloud. Instantaneous images taken from the time-lapsed movies of ice buildup were used along with the relevant thermodynamic data of air, water vapor and local icing condition to help evaluate how closely the proposed altitude scaling method could be used in ground based test facility to duplicate selected reference ICI features observed at specific location inside this engine at different scale altitudes. Discussions on observed limitation for engine icing scaling application from this test campaign and needed improvement are provided. A scaling test procedure to help identify potential ICI risk conditions and possible ice accretion locations of a new turbofan engine is evaluated in PSL.
\end{abstract}

\section{Introduction}

A key goal of the NASA Engine Icing Research is to better understand the complex physics and possible interaction of the icecrystal icing (ICI) phenomena that take place inside a modern turbofan engine in order to develop numerical simulation models of various fidelity, with the goal to determine possible engine icing onset conditions and locations; predict ice accretion locations, profiles and sizes; and evaluate/address design challenges to mitigate the risks [1]. The NASA Engine Icing Research team has continued developing its understanding of ice-crystal icing through a number of full scale engine test campaigns conducted in the PSL [2-7] and a series of fundamental ICI physics experimental studies conducted on a NACA 0012 airfoil in the NRC Research Altitude Test Facility (RATFac) and the NASA Propulsion Systems Laboratory (PSL) [813]. A simulated altitude engine icing test facility like the PSL enables highly controlled environmental simulations at relevant flight conditions to be examined. Instrumentation development to acquire details on the cloud generation in the facility and the ability to fully instrument an engine allows researchers better understand of the underlying physical mechanisms in order to further improve and validate the existing in-house engine ice accretion simulation and icing risk prediction codes. Those early research works formed the basis of the icing risk criteria used in the development of the NASA in-house 1D Icing Risk tool [14-18].

NASA, in collaboration with Honeywell and with the support of the International Ice Crystal Consortium, had successfully conducted two full engine test campaigns on an unmodified ALF502R-5 engine configuration [2-7]. Those studies gave an initial understanding of possible ICI features in a relevant engine icing environment. However this engine was an older design and featured a heated spinner which provided an additional source of liquid. This current study examines the Honeywell Uncertified Research Engine (HURE) which is a different turbofan engine design with a hidden core. This engine was never in production so there isn't any known ICI issues. Therefore this study served as a blind test that provided the NASA Engine Icing Research team a chance to assess how effectively the 1D Icing Risk tool could predict icing risk and how the proposed altitude scaling method could be used for full engine ICI testing at or near sea-level altitudes. This could help develop a method to test at sea-level facilities since availability and cost are important factors in an altitude simulation facility consideration.

The altitude scaling consideration for ICI is a condition scaling method used to determine the necessary scaled test conditions that enables similar ice accretion features from the reference condition chosen at selected location inside the engine compression system. Recently a thermodynamic model was developed by Tsao et al. [4] specifically for studying engine ICI phenomena and the model analysis has been examined with early fundamental ice crystal icing physics experimental data [8-9] and with selected data from the two previous engine ICI tests [1-2]. The ALF502 engine known to have ice-crystal accretion in the EGV2 TE region had helped calibrate the 1D Icing Risk tool to find the icing conditions at lower altitudes and illustrate that altitude scaling is possible in PSL to simulate the ice crystal accretion features. It may be of interest to note that in order to observe accretion at low altitude, the air static wet bulb temperature $T_{w b, \infty}$ had to be decreased for the ALF502 while $T_{w b, \infty}$ was increased

Page 1 of 9 
for the HURE test. This difference between the two engines could be due to different heat transfer effects between high altitude and $5 \mathrm{~K} \mathrm{ft}$. The focus of this study is to, using the 1D Icing Risk tool, show preliminary evaluation results of the proposed altitude scaling method at possible scaled icing conditions and accretion locations for the heavily instrumented HURE engine ICI test conducted in PSL in 2018.

\section{Proposed Scaling Parameters for Engine ICI}

\section{Key Equations for Similarity Parameter Consideration}

This aforementioned thermodynamic model for engine ICI study was primarily based on previous scaling work by Anderson [19] and Anderson and Tsao [20] using the Messinger's steady-state surface energy balance analysis [21] for super-cooled liquid water icing in both Appendix C and Super-cooled Large Drop (SLD) regimes. The expressions for key surface energy balance equations and the associated similarity parameters involved will be presented here without much discussion. Therefore, readers who are interested in the physical descriptions and detailed derivations of these parameters are referred to [4, 7, 19 and 20] and the references given therein. Several key modifications were made to the surface energy balance equations in order to account for possible interactions between the local air flow within the low/high pressure compressor flow passage and the ingested ice crystals from the engine inlet.

\section{(1) Freezing Dominated Regime}

The final expression of the freezing fraction of liquid melt at stagnation point region can be written in the following form

$$
n_{0}=\frac{1}{b_{0}^{*}}\left(T_{s}-T_{w b, 0}\right)-c_{0}^{*}
$$

in which $T_{w b, 0}$ denotes the total air wet bulb temperature and is given as

$$
T_{w b, 0}=\left(T_{\infty}+\frac{V_{\infty}^{2}}{2 c_{p, a i r}}\right)-\frac{h_{G}}{h_{c}}\left[\frac{\frac{p_{v, w s}}{T_{\infty}}-\left(\frac{P_{0}}{T_{0}}\right) \frac{p_{v, w \infty}}{P_{\infty}}(R H)}{\frac{1}{0.622}\left(\frac{P_{0}}{T_{0}}\right)-\left(\frac{p_{v, w s}}{T_{\infty}}\right)}\right] \Lambda_{v},
$$

and

$$
\begin{aligned}
& b_{0}^{*}=\frac{\dot{m}_{\text {imp }}(M R) \Lambda_{f}}{h_{c}}\left(\frac{I W C_{i} / \rho_{a}}{\left(I W C_{i}-V W C_{\text {gain }} / \rho_{a}\right)}\right), \\
& c_{0}^{*}=\left(\frac{\left(\frac{\gamma}{2} R T_{\infty}\right) M_{\infty}^{2}}{(M R) \Lambda_{f}}\right)\left(\frac{I W C_{i} / \rho_{a}}{\left(I W C_{i}-V W C_{\text {gain }}\right) / \rho_{a}}\right) .
\end{aligned}
$$

From Eq. (1), it is clear that both parameters $T_{w b, 0}$ and $M R$ can affect the accretion process however they are not unique. There are many likely combinations of $T_{w b, 0}$ and $M R$ that could lead to the same freezing fraction $n_{0}$. It is also noted that for a given local thermal

Page 2 of 9 profile, i.e. fixed $T_{w b, 0}$ and $M R$, the freezing fraction $n_{0}$ decreases as $\left(\mathrm{IWC}_{\mathrm{i}} / \rho_{\mathrm{a}}\right)$ increases. This non-dimensional term $\left(I W A R \equiv \mathrm{IWC}_{\mathrm{i}} / \rho_{\mathrm{a}}\right)$ suggests that for engine ICI problem the air density effect is also important. For the same IWAR value ingested by the engine, the local $\mathrm{IWC}_{\mathrm{i}}$ value increases as altitude goes from $45 \mathrm{~K}$ ft to $5 \mathrm{~K} \mathrm{ft}$ due to increasing air density value. It was necessary to increase the $\mathrm{IWC}_{\mathrm{i}}$ to maintain the $I W A R$ when going from $45 \mathrm{~K} \mathrm{ft}$ to $5 \mathrm{~K} \mathrm{ft}$, see Table 5 below. This effect was first noticed and reported by Veres et al. [17] in their recent engine icing analysis work in terms of the ice-water flow rate to air flow rate ratio, IWAR, from the heavily instrumented ALF502 (S/N LF11) engine icing test data. This suggests that the most important parameter affecting the ice crystal accretion process is the freezing fraction $n_{0}$.

\section{(2) Melting Dominated Regime}

The expression of the melting fraction of ice particle at stagnation point region can be written in the following form

$$
m_{0}=\frac{M R}{b_{0}^{*}\left(1-M R-\left(\frac{V W C_{\text {gain }}}{I W C_{i}}\right)\right)}\left(T_{w b .0}-T_{s}\right)+\frac{M R}{\left(1-M R-\left(\frac{V W C_{\text {gain }}}{I W C_{i}}\right)\right)} c_{0}^{*}
$$

Similar to the freezing dominated process, Eq. (2) also shows that for melting dominated process on icing surfaces the melting fraction $m_{0}$ is the most important parameter. Additionally, it is noticed that the most effective variables from the test facility to control the resulting ICI feature are the IWAR and $T_{w b, 0}$.

\section{Experiment Description}

\section{Facility Description}

The HURE engine ice-crystal icing test was conducted in the NASA Glenn Research Center Propulsion Systems Laboratory Cell 3 (PSL3). PSL is a direct-connect altitude test chamber that was modified with an icing cloud generation system. Details on the facility capabilities can be found in [22] and [23] and are briefly highlighted in Table 1.

PSL can generate ICI conditions through a spray nozzle freeze out methodology which is described in [24]. The facility icing operation envelope is illustrated in Figure 1. Prior to the test, a cloud calibration was conducted to characterize the cloud for the requested icing conditions and gain further facility experience by exploring the PSL parameter space. Details of this calibration can be found in a recent publication by Van Zante et al. [24].

Table 1. PSL-3 Capability

\begin{tabular}{|l|c|c|}
\hline Specification & Min & Max \\
\hline Engine / Rig Dia. (in | cm) & $24 \mid 60$ & $72 \mid 180$ \\
\hline Air Flow Rate $(\mathrm{lbm} / \mathrm{s} \mid \mathrm{kg} / \mathrm{s})$ & $10 \mid 5$ & $330 \mid 150$ \\
\hline Altitude, pressure $(\mathrm{kft} \mid \mathrm{km})$ & $4 \mid 1.2$ & $50 \mid 15$ \\
\hline Total Temp $\left({ }^{\circ} \mathrm{F} \mid{ }^{\circ} \mathrm{C}\right)$ & $-60 \mid-50$ & $50 \mid 10$ \\
\hline Mach Number & 0.15 & 0.80 \\
\hline TWC $\left(\mathrm{g} / \mathrm{m}^{3}\right)$ & 0.5 & $8.0^{*}$ \\
\hline MVD (um) & 15 & $>100^{*}$ \\
\hline
\end{tabular}

* Evidence that probe under-measured

${ }^{\#}$ Particles larger than 60 microns are NOT fully glaciated 


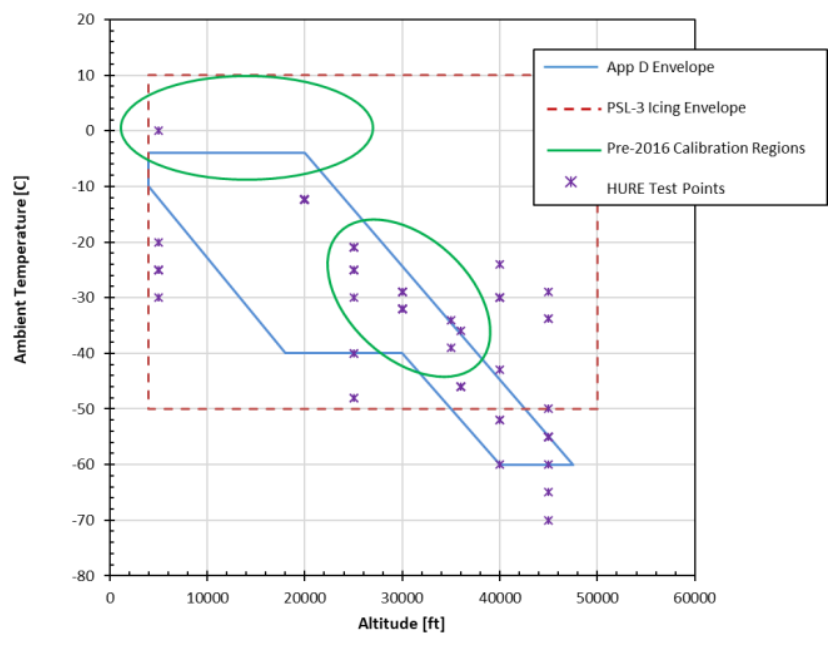

Figure 1. PSL-3 Icing Envelope

\section{Test Article Description}

The Honeywell Uncertified Research Engine (HURE) is a turbofan engine that features a hidden core design. This design with an inlet gooseneck feature keeps the core less exposed, see Figure 2. Details about the test experimental set-up is described in [25].

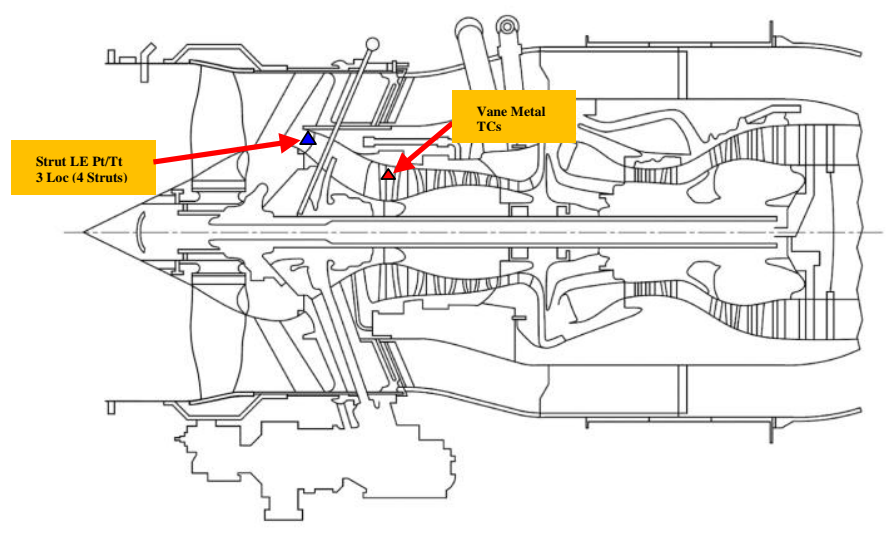

Figure 2. HURE Engine Cross-Section (Courtesy Honeywell Engines)

\section{Instrumentation Description}

The engine was fully instrumented with typical aero-research instrumentation. This paper will describe the instrumentation relevant to the local IC icing feature assessment for scaling evaluation purpose. Static pressure data were obtained on the front frame hub leading and trailing edge and along the HPC outer shroud at rotors 2 and 3. Total temperature data were acquired at the engine inlet, at four circumferential positions at the splitter-lip strut leading edge at three radial locations and aft of the fan in the bypass duct with two $\mathrm{T} 2$ sensors. Metal temperature data were acquired at four circumferential locations at the HPC IGV, and stator vanes 1 and 2. Humidity measurements were obtained at the core inlet and in the HPC exit. A simple layout of temperature measurement instrumentation used in this study is highlighted in Figure 2.

Important measurements of ice crystal particle size distribution after passing through an engine fan were obtained and the details regarding the method and analysis is given in [26]. This data would provide needed information on the particle MVD size of ice crystals ingested into the core.

\section{Scaling Evaluation of Ice-Crystal Icing for a New Engine}

The HURE engine is a prototype engine for research and development purpose with many notional design features that has not entered for production. Therefore it does not have any known ICI information or flight data of field events that could help the HURE engine test team to quickly identify possible range of atmospheric and engine operating conditions as well as the most likely IC icing locations (e.g. highest IC cloud impinging mass flux locations) inside the engine compression system. This provides an opportunity for the team to develop a test procedure in PSL to identify potential engine ICI test points in Appendix D conditions and then obtain corresponding altitude engine performance and icing effect data for analytical modeling tool development.

For determining the ICI test matrix the NASA team utilized its inhouse 1D engine icing risk assessment code, COMDES-MELT, to generate atmospheric and engine operating conditions at different altitudes that could enable ice-crystal icing to occur at several selected stations within the compression system, as highlighted in Figure 3. Details of this extensive computational prediction analysis work was reported in 2017 by Veres et al. [27] prior to the HURE test entry. After the test, Veres et al. also performed a post-test data analysis of 57 Escort test points that were taken at distinct operating conditions in PSL at altitudes from $5 \mathrm{~K}$ ft to $45 \mathrm{~K} \mathrm{ft}$. The detailed analysis results for these test data points with the Honeywell Customer Deck and with the COMDES-MELT codes were reported in Reference [28].

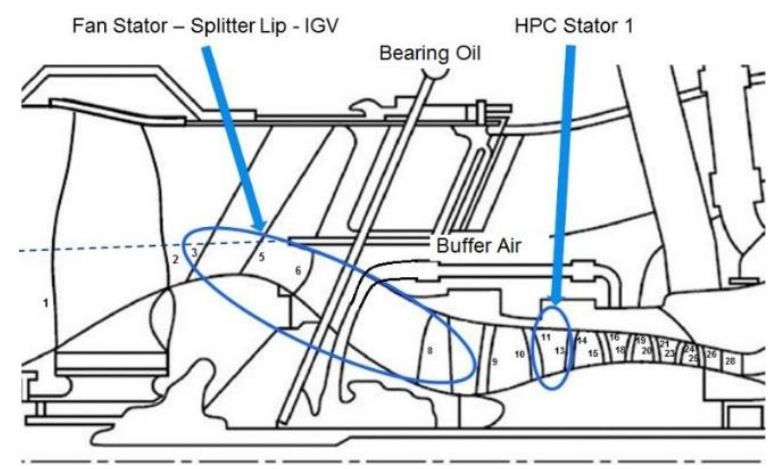

Figure 3. Selected ICI Meridional Stations within HURE Compression System $(\operatorname{Ref}[27])$

As shown from Eqns. (1) and (2), for possible similarity of ice crystal accretion on specific unheated surface location within the engine compression system flow passage, it is necessary for the scale test to simulate the geometry, the flow field, the ice/water particle trajectories, the total water catch, the heat transfer and, probably, the surface phenomena of the desired reference icing condition. However most of the needed information in order to conduct proper scaling calculation for this HURE engine were not known or available at the time. An alternative approach to find potential scale test conditions was established as follows:

(1) A potential IC icing risk condition at $45 \mathrm{~K} \mathrm{ft}$ was selected as the reference condition for this scaling study. The reference IC accretion features will be evaluated at those prescribed camera view locations

Page 3 of 9 
inside this engine. It covers the fan stator region at station 3-5, the splitter-lip strut LE at station 6 and the HPC IGV LE at station 8 in COMDES-MELT's station number notation shown in Figure 3.

(2) Three scaled test conditions with similar engine ICI risk at altitudes of $36 \mathrm{~K}, 25 \mathrm{~K}$ and $5 \mathrm{~K} \mathrm{ft}$ with best matching engine fan-core and LPC/HPC operation characteristics (ex: the engine fan face Mach number $\mathrm{M}_{\mathrm{ff}}$, the corrected engine fan face mass flow rate $\mathrm{W}_{\text {cor }}$, and the corrected engine fan rotational speed $\mathrm{N} 1_{\text {cor }}$ ) from the reference condition were calculated using the COMDES-MELT code to best match the following key icing parameters of the reference condition at those three selected locations:

a. the local total wet bulb temperature $T_{w b, 0}$,

b. the local IC cloud melt ratio $M R$, and

c. the engine fan face IWAR of the IC cloud (as an approximation of the local IWAR value). When the PSL were able to estimate the TWC value ingested into the core with the Light Extinction Probe (LEP) system [25], it should match the local IWAR.

(3) A parametric sweep of IWC, MVD, N1 and Tplaround each proposed scale condition will be performed (within the facility operation limit) to ensure sufficient coverage of local reference icing conditions at prescribed icing risk locations would be simulated to allow reasonable evaluation of the proposed scaling method.

\section{The Reference Condition ICI Features}

During the first two days of HURE ICI test campaign, the team tested a number of potential ICI test points, chosen from Reference [27], in 1-3 minutes short spray in the PSL to identify icing cases to be used as ICI anchor points for detailed parametric studies.

For the reference condition at $45 \mathrm{~K} \mathrm{ft}$, two potential ICI conditions were considered, Escort readings 121 and 156. The corresponding atmospheric and engine operating conditions run in PSL are listed in Table 2 which includes facility measured parameters (M) like altitude, flight Mach number, ambient air temperature, plenum air temperature and pressure and some facility calculated parameters $(\mathrm{C})$ like IC cloud total water content, IC cloud MVD size and IWAR. The team evaluated the corresponding ICI accretion features and the extent of icing coverage over those three camera view areas and then picked the best one for scaling study.
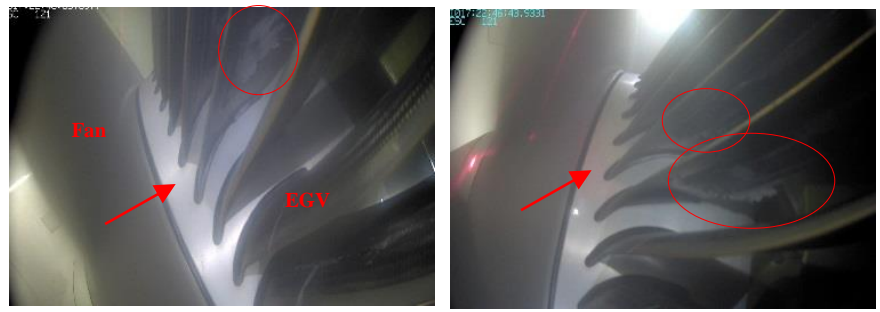

Figure 4. Escort 121, Screenshots of Fan Stator (Stator 2 \& Stator 4 Views) Showing Quick Ice Buildup on the Pressure Side of EGV.
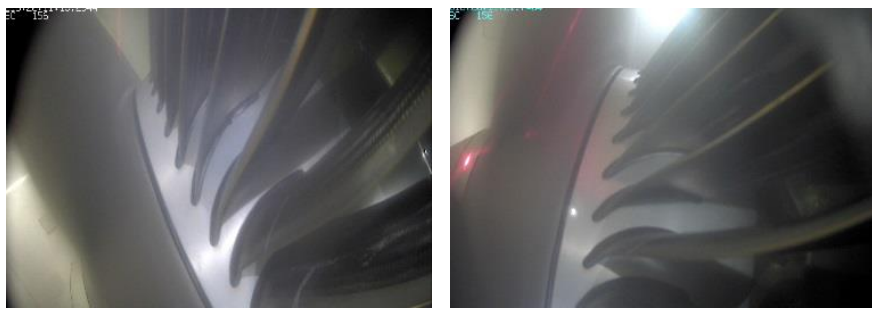

Figure 5. Escort 156, Screenshots of Fan Stator (Stator 2 \& Stator 4 View) Showing No Ice Accretion Formed on the EGV.
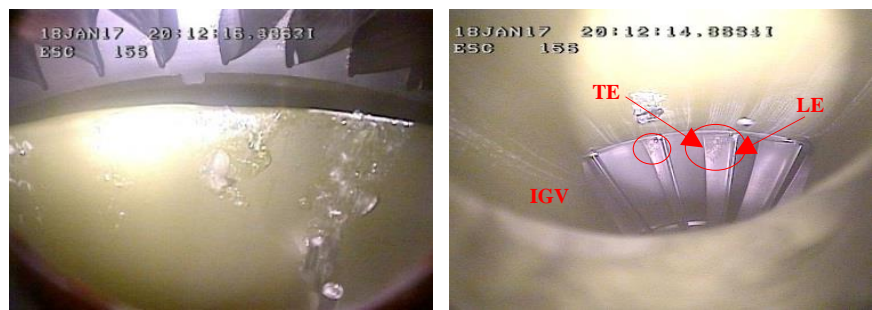

Figure 6. Escort 156, Screenshots of Splitter-Lip Shroud (left) and IGV Surfaces (right) Showing Firm Ice Accretion and Runback Water.

Table 2. Two Potential Reference ICI Conditions at $45 \mathrm{~K} \mathrm{ft}$.

\begin{tabular}{|c|c|c|c|c|c|c|c|c|}
\hline $\begin{array}{c}\text { Esc } \\
\text { Rdg }\end{array}$ & $\begin{array}{c}\text { Alt } \\
\text { Kft }\end{array}$ & $\mathbf{M}_{\text {FLT }}$ & $\begin{array}{c}\mathbf{T}_{\text {amb }} \\
{ }^{\circ} \mathbf{F}\end{array}$ & $\begin{array}{c}\mathbf{T}_{\mathbf{P L}} \\
{ }^{\circ} \mathbf{F}\end{array}$ & $\begin{array}{c}\mathbf{P}_{\mathbf{P L}} \\
\mathbf{P s i a}\end{array}$ & $\begin{array}{c}\text { IWAR } \\
\left(\mathbf{1 0}^{-3}\right)\end{array}$ & $\begin{array}{c}\mathbf{T W C} \\
\mathbf{g} / \mathbf{m}^{\mathbf{3}}\end{array}$ & $\begin{array}{c}\text { MVD } \\
\boldsymbol{\mu m}\end{array}$ \\
\hline 121 & 45.1 & 0.81 & -31.6 & 24.4 & 3.27 & 5.5 & 1.5 & 28 \\
\hline 156 & 45.2 & 0.77 & -56.3 & -9.5 & 3.13 & 9.7 & 2.8 & 29 \\
\hline
\end{tabular}

The Escort is the PSL data recording system. The Escort reading (Esc rdg) 121 is a case where ice-crystal melting is dominant inside the engine core flow passage. Quick ice buildup with infrequent ice shedding was observed on the pressure side of the fan stators (EGV) as shown in Figure 4, further into the splitter-lip shroud and strut LE region rapid ice shedding with discrete small white ice deposits with no discernable growth was observed along the splitter lip, and no ice was observed in the HPC IGV area where the surface metal temperature was well above freezing.

The Escort reading 156, however, is a case where IC melting is not as strong as case 121 and freezing of IC melt on the surface is occurring inside the engine core flow passage. No ice accretion was observed on the fan stator vanes where the IC particle temperature was still sub-freezing with very little melt and the fan stator vanes were also dry and mildly cold. The ambient temperature was $25^{\circ} \mathrm{F}$ colder than Escort reading 121 with almost twice the TWC resulting in a higher $I W A R$. Thus no ice was collected or accreted on the fan stators as shown in Figure 5. The COMDES-MELT analysis also predicted that there would be no ice accretion in the fan stator region for this case 156. In the splitter-lip and strut LE region very glazy ice accretion started to form on the splitter-lip region and lots of water runback was seen on the splitter-lip shroud surface area, see the left image in Figure 6. Also very little amount of firm ice accretion was formed on the IGV LE tip area as well as on the pressure side TE region of the vanes as illustrated in the right image of Figure 6.

Page 4 of 9 
It was noted in Reference [28] that ice accretion was observed on the front frame components near the splitter-lip at lower static wet bulb temperatures than was expected, based on the Icing Wedge minimum threshold of $492{ }^{\circ} \mathrm{R}$. In addition, the accretion occurred at static air temperatures well below freezing, thus no or very little particle melting could have occurred due to heating from the air alone. The aluminum front frame may have received heat from additional sources besides the air, but this process is not well understood for this engine. It is possible that the ice accretion in that region was not an adiabatic process which was assumed in the 1D simulations. During testing, in order to compensate for the lack of a heat transfer model in the COMDES-MELT code, the target static wet bulb temperature $\left(T_{w b, \infty}\right)$ for ice to accrete in the front frame region was reduced to 468 ${ }^{\circ} \mathrm{R}$. This was $24^{\circ} \mathrm{R}$ below the Icing Wedge minimum threshold of $492{ }^{\circ} \mathrm{R}$. The new target $T_{w b, \infty}$ was determined by the analysis of one of the operating points where ice accreted at the splitter-lip and shroud region. Using COMDES-MELT, new testing conditions were rapidly derived prior to further testing, and the test matrix was modified. This was successful in enabling ice to accrete in the front frame components (splitter-lip and shroud region). For post-test data analysis, a simple bulk heat transfer model was developed to estimate the wall metal surface temperature [28]. This was done in order to compare it to previous engine tests which had measured wall temperatures between $492{ }^{\circ} \mathrm{R}$ to $501^{\circ} \mathrm{R}$ during ice accretion.

However the observation of water runback on the splitter-lip surface area was different from what the COMDES-MELT calculation of Escort Rdg 156 case has shown that the IC particles would not experience any melting from the airflow in the core flow passage from the splitter-lip to HPC IGV regions (i.e. $M R=0$ from stations 58). As mentioned earlier there was possible unknown heat transfer mechanism not accounted for by the COMDES-MELT code in this area that could promote melting of IC particles. Jorgenson et al. [28] has provided an order of magnitude estimate of possible heat transfer model hypothesis in this region (i.e. assuming a non-adiabatic wall) to promote the observed IC melting as seen in Figure 6. It was decided then for finding all scaled test conditions the COMDESMELT code was adjusted by the selected reference condition.

Table 3 shows the facility measured air total temperatures at stations $3 \& 6$ and the pre-spray metal surface temperature at station 8 that collectively provide the initial compression system thermal energy for possible melting of ingested IC cloud, and also includes the COMDES-MELT calculated total wet bulb temperatures at station 5 $\& 6$ and the measured metal surface temperature after a minute of IC spray at station 8 which represent the final thermal equilibrium states of the ingested IC cloud and the compression system. Clearly the thermal data from the Escort Rdg121 case exhibits a melting dominant ICI features but the Escort Rdg 156 case, with $25^{\circ} \mathrm{F}$ lower inlet temperature, displays a potential low freezing ICI features.

It is worth noting that in finding the best ICI case as the reference condition, it was recognized from the videos that there are several key areas for ICI in the fan stator (adiabatic region), splitter-lip and shroud region (non-adiabatic region) and the HPC IGV (possibly affected by melting ice from non-adiabatic region) as highlighted in Figures 4 and 6. David Rigby at el. [29] presents a numerical study of IC ingestion into HURE with more details given in the paper that corroborates these observations. Based on the reference ICI features described in Table 3 and further considering the air mass flow rate constraint found at running $5 \mathrm{~K}$ ft altitude simulation in PSL requires that the fan speed and flight Mach number must be reduced significantly in order to duplicate the reference ice accretion, therefore the Escort Rdg 156 case is chosen to be the reference condition for scaling study of ICI.
Table 3. The $\mathrm{T}_{0}, \mathrm{~T}_{\mathrm{wb} 0}, \mathrm{~T}_{\mathrm{IGV}}$ Values and the Observed ICI Features at Station 3 , $5,6 \& 8$ for Those Two Potential Reference ICI Conditions at $45 \mathrm{~K} \mathrm{ft}$.

\begin{tabular}{|c|c|c|c|c|c|c|c|}
\hline $\begin{array}{l}\text { Esc } \\
\text { Rdg }\end{array}$ & $\begin{array}{l}\mathbf{T}_{0,3} \\
{ }^{\circ} \mathbf{F}\end{array}$ & $\begin{array}{l}\mathbf{T}_{\mathrm{wb} 0,5} \\
{ }^{\circ} \mathbf{F}\end{array}$ & $\begin{array}{l}\mathbf{T}_{0,6} \\
{ }^{\circ} \mathbf{F}\end{array}$ & $\stackrel{T_{\mathrm{wb} 0,6}}{{ }^{\circ} \mathrm{F}}$ & $M R_{6}$ & $\begin{array}{c}\mathbf{T}_{\text {IGV }} \\
\text { Metal, } \\
\text { Pre Spray, } \\
{ }^{\circ} \mathbf{F}\end{array}$ & \begin{tabular}{|c|}
$T_{\text {IGV }}$ Metal, \\
Spray on, @ \\
60 sec, \\
${ }^{\circ} \mathrm{F}$
\end{tabular} \\
\hline & M & COMDES & $\mathrm{M}$ & COMDES & COMDES & $\mathrm{M}$ & $\mathrm{M}$ \\
\hline 121 & 115.5 & 52.0 & 117.3 & 46.4 & 0.17 & 115.0 & 70.1 \\
\hline 156 & 35.2 & 21.8 & 49.8 & 19.5 & 0.0 & 51.5 & 32.6 \\
\hline $\begin{array}{l}\text { Icing } \\
\text { Area }\end{array}$ & \multicolumn{3}{|c|}{$\begin{array}{l}\text { Fan Stator } \\
\text { (EGV) }\end{array}$} & \multicolumn{2}{|c|}{$\begin{array}{l}\text { Splitter-Lip Shroud } \\
\text { \& Strut LE }\end{array}$} & \multicolumn{2}{|c|}{$\begin{array}{l}\text { HPC } \\
\text { IGV }\end{array}$} \\
\hline 121 & \multicolumn{3}{|c|}{$\sqrt{ }$} & \multicolumn{2}{|l|}{$\sqrt{ }$} & \multicolumn{2}{|r|}{$\bar{X}$} \\
\hline 156 & \multicolumn{3}{|c|}{$\bar{X}$} & \multicolumn{2}{|l|}{$\sqrt{ }$} & \multicolumn{2}{|r|}{$\overline{\sqrt{ }}$} \\
\hline
\end{tabular}

Table 4. The Matching Similarity Parameters between Reference and Scale Test Conditions

\begin{tabular}{|c|c|c|c|}
\hline $\begin{array}{c}\text { Esc } \\
\text { Rdg }\end{array}$ & $\begin{array}{c}\mathbf{T}_{\text {wb0,6 }} \\
{ }^{\circ} \mathbf{F}\end{array}$ & $\mathbf{M R}_{\mathbf{6}}$ & $\begin{array}{c}\text { IWAR } \\
\left(\mathbf{1 0}^{-3}\right)\end{array}$ \\
\hline 156 & 19.5 & 0 & 9.7 \\
\hline 284 & 19.1 & 0 & 11.0 \\
\hline 279 & 21.7 & 0 & 9.0 \\
\hline 242 & 24.2 & 0 & 9.1 \\
\hline
\end{tabular}

\section{The Scaled Condition ICI Features}

Three scaled test conditions at altitudes of $36 \mathrm{~K}, 25 \mathrm{~K}$ and $5 \mathrm{~K}$ ft were best matching the splitter-lip and strut LE station's total wet bulb temperature (i.e. $\mathrm{T}_{\mathrm{wb} 0,6}$ ), IC particle melt ratio (i.e. $M R_{6}$ ) and the engine fan face IWAR of the reference condition (Esc Rdg 156 case).

Table 5. The Reference and Scaled Test Conditions at 45K, 36K, 25K and 5K $\mathrm{ft}$.

\begin{tabular}{|c|c|c|c|c|c|c|c|c|}
\hline $\begin{array}{c}\text { Esc } \\
\text { Rdg }\end{array}$ & $\begin{array}{c}\text { Alt } \\
\mathbf{K f t}\end{array}$ & $\mathbf{M}_{\mathrm{FLT}}$ & $\begin{array}{c}\mathbf{T}_{\mathrm{amb}} \\
{ }^{\circ} \mathbf{F}\end{array}$ & $\begin{array}{c}\mathbf{T}_{\mathbf{P L}} \\
{ }^{\circ} \mathbf{F}\end{array}$ & $\begin{array}{c}\mathbf{P}_{\mathbf{P L}} \\
\mathbf{P s i a}\end{array}$ & $\begin{array}{c}\text { IWAR } \\
\left(\mathbf{1 0}^{-3}\right)\end{array}$ & $\begin{array}{c}\mathbf{T W C} \\
\mathbf{g} / \mathbf{m}^{3}\end{array}$ & $\begin{array}{c}\mathbf{M V D} \\
\boldsymbol{\mu m}\end{array}$ \\
\hline 156 & 45.2 & 0.77 & -56.3 & -9.5 & 3.13 & 9.7 & 2.8 & 29 \\
\hline 284 & 36.2 & 0.61 & -46.9 & -16.2 & 4.21 & 11.0 & 4.2 & $\mathrm{~N} / \mathrm{A}$ \\
\hline 279 & 25.0 & 0.60 & -49.6 & -19.7 & 6.99 & 9.0 & 5.8 & 55 \\
\hline 242 & 4.92 & 0.20 & -26.2 & -22.9 & 12.60 & 9.1 & 10.7 & 52 \\
\hline
\end{tabular}


The best matching similarity parameters for ICI scaling application were shown in Table 4 and the resulting atmospheric and engine operating conditions run in PSL were shown in Table 5. Melt ratio was not considered a key parameter for icing risk for this region, since the melting of the ice particle not coming from the air but was most likely coming from their impact with a heated surface.
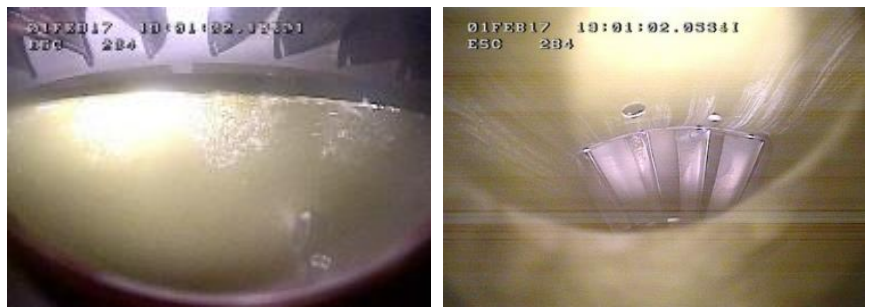

Figure 7. Escort 284, Screenshots of Splitter-Lip Shroud (left) and IGY (right) Surfaces Showing Firm Ice Accretion and Some Running Wet.
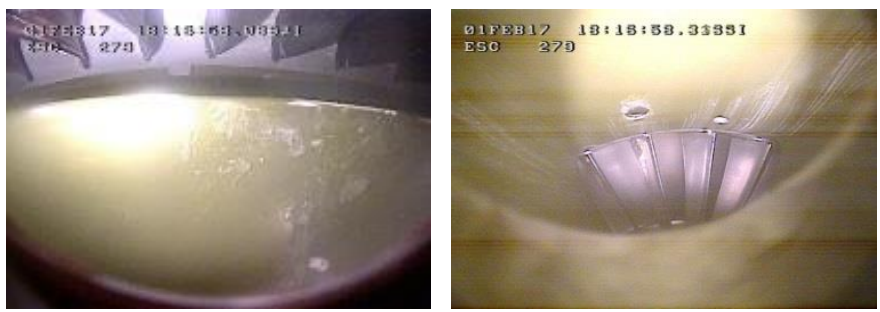

Figure 8. Escort 279, Screenshots of Splitter-Lip Shroud (left) and IGV (right) Surfaces Showing Firm Ice Accretion and Some Running Wet.
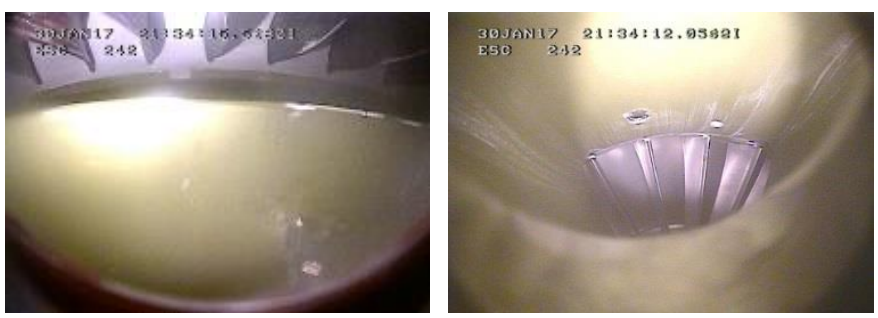

Figure 9. Escort 242, Screenshots of Splitter-Lip Shroud (left) and IGV (right) Surfaces Showing Firm Ice Accretion with Very Little Running Wet.

Similar to the aforementioned reference condition ICI features the Escort Rdg 284, 279 and 242 are cases where ice-crystal freezing is dominant inside the engine core flow passage as well. No ice deposit or accretion was observed on the fan stator vanes (due to low ambient air temperature). In the splitter-lip and strut LE region firm glaze ice accretion started to form on the splitter-lip region and some runback water was observed on the splitter-lip shroud surface area for Escort Rdg 284 \& 279, see Figures 7-8. But for the Escort Rdg 242 case it showed very little wetting on the splitter-lip region where only small firm glaze ice accretion was observed in Figure 9. The calculated wet bulb temperatures were below freezing for these three cases. Again this is a region where other heated components in the flow path may contribute greatly to the melting of ice particles when they impact these heated surfaces.

As stated in the proposed scaling test procedure a parametric sweep of two most ICI sensitive facility variables (i.e. TWC and $\mathrm{T}_{\mathrm{pl}}$ ) were performed around the case 242 to see how much change was needed for each variable in order to reproduce the selected reference ICI features at this altitude of $5 \mathrm{~K} \mathrm{ft}$.

In the Escort Rdg 243 case the ambient temperature was raised by 5 ${ }^{\circ} \mathrm{F}$ and in Escort Rdg 245 case the TWC was increased by 15\%. Both conditions resulted in firm glaze ice accretion observed with some surface water runback on the splitter-lip region, see Figure 10.
Finally the Table 6 shows, for the reference and all three scaled test conditions, the measured air total temperatures at stations $3 \& 6$, the measured pre-spray metal surface temperature at station 8 , the calculated total wet bulb temperatures at station $5 \& 6$ and the measured metal surface temperature after one minute of IC spray at station 8 .
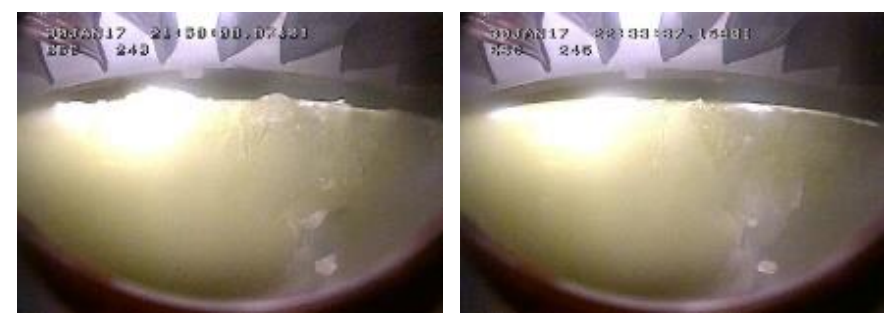

Figure 10. Escort 243 (left) and 245 (right) cases, Screenshots of Splitter-Lip Shroud Surfaces Showing Firm Glaze Ice Accretion with Some Running Wet.

Similar to the reference case ICI features, those three scaled test conditions all exhibit freezing dominant ICI features in general. However for the near sea level $5 \mathrm{~K} \mathrm{ft}$ altitude test point (i.e. Esc Rdg 242), the IC cloud melting before reaching to the splitter-lip region is not as much as the reference condition of the other two higher altitude scaled test points have. By raising the ambient air temperature $5^{\circ} \mathrm{F}$ warmer or increasing the TWC by $15 \%$ seems to provide the needed portion of IC melt in the splitter-lip surface area.

From the preliminary evaluation it is found that the PSL has developed sufficient control of the air temperature, the TWC and MVD of an IC spray, as well as the cloud uniformity for most of the atmospheric conditions within its icing envelope (as shown in Figure 1) for various ICI simulations. Acceptable scaling results were obtained even at its $5 \mathrm{~K} \mathrm{ft}$ operation limit point. The scaling evaluation of ICI features on this engine in PSL suggests that altitude scaling is possible if the engine core flow passage (mainly in the low pressure compression section of the engine) surface heat transfer feature is available and properly accounted for by the NASA's inhouse 1D Engine Icing Risk assessment code, COMDES-MELT This would enable PSL or a sea level engine test facility to simulate the important ice crystal accretion features and the associated ICI effects on engine performance. In particular, the scaling test procedure used in PSL for this engine test has helped identify potential icing risk conditions and possible ice accretion locations for a new turbofan engine design where no ICI information is available in advance.

It should be noted that the PSL engine icing facility continues working on improving its ability to have better icing cloud quality. The in-house higher fidelity numerical icing simulation codes are under development and they are still limited by current measurement capability and larger test data uncertainty for rigorous model validation purpose. In addition, there is no robust measurement method to acquire data in the engine core flow passage locations where initial ice buildup is first occurred due to the complexity and harsh engine environment. With these constraints in mind, the images and the time-lapsed movies of ice formation from the cameras represent the only available visual characterization of resulting ice shapes. The qualitative ice shape comparison allows one to assess how well this altitude scaling method could replicate the reference ice crystal accretion features observed. 
Table 6. The $\mathrm{T}_{0}, \mathrm{~T}_{\mathrm{wb} 0}, \mathrm{~T}_{\mathrm{IGV}}$ Values and the Observed ICI Features at Station 3 $5,6 \& 8$ for Reference and All Three Scaled Test Conditions

\begin{tabular}{|c|c|c|c|c|c|c|c|}
\hline $\begin{array}{l}\text { Esc } \\
\text { Rdg }\end{array}$ & $\begin{array}{l}\mathbf{T}_{\mathbf{0 , 3}} \\
{ }^{\circ} \mathbf{F}\end{array}$ & $\stackrel{\mathbf{T}_{\mathrm{wb} 0,5}}{\stackrel{\circ}{\circ} \mathbf{F}}$ & $\begin{array}{l}\mathbf{T}_{0,6} \\
{ }^{\circ} \mathbf{F}\end{array}$ & $\begin{array}{c}\mathbf{T}_{\mathrm{wb} 0,6} \\
{ }^{\circ} \mathbf{F}\end{array}$ & $M R_{6}$ & $\begin{array}{c}\text { T}_{\text {IGV }} \\
\text { Metal, } \\
\text { Pre } \\
\text { Spray, } \\
{ }^{\circ} \mathbf{F} \\
\end{array}$ & $\begin{array}{c}\text { T IGV } \\
\text { Metal, } \\
\text { Spray on, } \\
\text { @ } 60 \text { sec, } \\
{ }^{\circ} \mathrm{F}\end{array}$ \\
\hline & $\mathrm{M}$ & COMDES & $\mathrm{M}$ & COMDES & COMDES & $\mathrm{M}$ & M \\
\hline 156 & 35.2 & 21.8 & 49.8 & 19.5 & 0.0 & 51.5 & 32.6 \\
\hline 284 & 35.8 & 20.6 & 41.8 & 19.1 & 0.0 & 42.4 & 31.2 \\
\hline 279 & 36.4 & 21.8 & 36.3 & 21.7 & 0.0 & 34,5 & 32.2 \\
\hline 242 & 35.8 & 26.9 & 33.2 & 24.2 & 0.0 & 32.0 & 32.2 \\
\hline $\begin{array}{l}\text { Icing } \\
\text { Area }\end{array}$ & & $\begin{array}{c}\text { Fan Stator } \\
\text { (EGV) }\end{array}$ & \multicolumn{3}{|c|}{$\begin{array}{c}\text { Splitter-Lip Shroud } \\
\text { \& Strut LE }\end{array}$} & \multicolumn{2}{|c|}{$\begin{array}{l}\text { HPC } \\
\text { IGV }\end{array}$} \\
\hline 156 & & $\mathrm{X}$ & \multicolumn{3}{|c|}{$\sqrt{ }$} & \multicolumn{2}{|c|}{$\sqrt{ }$} \\
\hline 284 & & $\mathrm{X}$ & \multicolumn{3}{|c|}{$\sqrt{ }$} & \multicolumn{2}{|c|}{$\sqrt{ }$} \\
\hline 279 & & $\mathrm{X}$ & \multicolumn{3}{|c|}{$\sqrt{ }$} & \multicolumn{2}{|c|}{$\sqrt{ }$} \\
\hline 242 & & $\mathrm{X}$ & \multicolumn{3}{|c|}{$\sqrt{ }$} & \multicolumn{2}{|c|}{$\sqrt{ }$} \\
\hline
\end{tabular}

\section{Conclusions}

Preliminary evaluation results of the proposed altitude scaling method for studying a full scale turbofan engine ICI features is presented from a heavily instrumented engine test conducted in the NASA Glenn Research Center Propulsion Systems Laboratory (PSL) during January of 2018.

It is shown from the evaluation that there exist two distinct types of ice formation for this engine: (1) when the icing surface is dominated by the freezing of IC melt from fully or partially melted impinging ice crystals, the ice structure is formed from accretion with strong adhesion to the surface, for example the Escort reading 156 case, and (2) when the icing surface is dominated by the further melting of ice crystals, the ice structure is formed from accumulation of un-melted ice crystals with relatively weak bonding to the surface, for example the Escort reading 121 case.

A proposed scaling test procedure was evaluated for this engine ICI study:

1. A potential IC icing risk condition at $45 \mathrm{k} f \mathrm{ft}$ was selected as the reference condition for this scaling study. The reference IC accretion features were evaluated at those prescribed camera view locations inside this engine.

2. Three scaled test conditions with similar engine ICI risk at altitudes of $36 \mathrm{k}, 25 \mathrm{k}$ and $5 \mathrm{k}$ ft were calculated using the COMDES-MELT code that was adjusted by the selected reference condition to best match the following three key icing parameters of the reference condition at the HPC IGV location:

i. the local total wet bulb temperature $T_{w b, 0}$,

ii. the local IC cloud melt ratio $M R$, however noticed that for this engine due to the additional heat from the splitter-lip region non-zero $M R$ of IC cloud from COMDES-MELT calculation was not possible for all cases since inlet conditions were adjusted to get a
$24{ }^{\circ} \mathrm{R}$ temperature drop in air static wet bulb temperature $T_{w b, \infty}$ in the splitter-lip shroud strut region, and

iii. the engine fan face IWAR of the IC cloud

3. A parametric sweep of IWC, MVD, N1 and $\mathrm{T}_{\mathrm{pl}}$ around each proposed scale condition was performed (within the facility operation limit) to ensure sufficient coverage of local reference icing conditions at prescribed icing risk locations.

The scaling evaluation of ICI features on this engine in PSL illustrates that altitude scaling is possible for PSL or a sea level engine test facility to simulate the important ice crystal accretion features and the associated ICI effects on engine performance. It was also shown from $5 \mathrm{~K} \mathrm{ft}$ scaled test results that due to the additional heat from the splitter-lip region, the scaled test condition (i.e. Escort Rdg 242 case) had to make some change, either by raising the ambient air temperature $5{ }^{\circ} \mathrm{F}$ warmer (i.e. Escort Rdg 243 case) or increasing the TWC by $15 \%$ (i.e. Escort Rdg 245 case) to replicate the firm glaze ice accretion with some surface runback water on the splitter-lip region that was observed in the reference condition (i.e. Escort Rdg 156 case). Thus for future engine ICI studies, it is strongly suggested that the dry-air performance and heat transfer characteristics of the low pressure compression system should be available for complete IC icing risk analysis. Finally, a scaling test procedure was proposed and evaluated in PSL to help identify potential icing risk conditions and possible ice accretion locations for a new turbofan engine design where no ICI information is available in advance.

\section{References}

1. Flegel, A. B., "Ice Crystal Icing Research at NASA Glenn Research Center," 9th AIAA Atmospheric and Space Environments Conference, AIAA 2017-4085, June 2017.

2. Oliver, M. J. "Validation Ice Crystal Icing Engine Test in the Propulsion Systems Laboratory at NASA Glenn Research Center," 6th AIAA Atmospheric and Space Environments Conference, AIAA-2014-2898, June 2014.

3. Goodwin, R.V., Dischinger, D.G., "Turbofan Ice Crystal Rollback Investigation and Preparations Leading to Inaugural Ice Crystal Engine Test at NASA PSL-3 Facility," 6th AIAA Atmospheric and Space Environments Conference, AIAA-20142895, June 2014.

4. Tsao, J., Struk, P. M., and Oliver, M. J., "Possible Mechanisms for Turbofan Engine Ice Crystal Icing at High Altitude," 6th AIAA Atmospheric and Space Environments Conference, AIAA-2014-3044, June 2014.

5. Flegel, A.B., Oliver, M.J., "Preliminary Results from a Heavily Instrumented Engine Ice Crystal Icing Test in a Ground Based Altitude Test Facility," 8th AIAA Atmospheric and Space Environments Conference, AIAA 2016-3894. NASA/TM-201629132.

6. Goodwin, R.V., Fuleki, D., "Turbofan Ice Crystal Rollback Investigation and Preparations Leading to the Second, Heavily Instrumented, Ice Crystal Engine Test at NASA PSL-3 test Facility," 8th AIAA Atmospheric and Space Environments Conference, AIAA-2016-3892, June 2016.

7. Tsao, J., "Preliminary Evaluation of Altitude Scaling for Turbofan Engine Ice Crystal Icing," 9th AIAA Atmospheric and Space Environments Conference, AIAA 2017-4086, June 2017.

8. Struk, P., Currie, T., Wright, W. B., Knezevici, D. C., Fuleki, D., Broeren, A., Vargas, M., and Tsao, J. "Fundamental Ice Crystal Accretion Physics Studies," SAE 2011 International Conference on Aircraft and Engine Icing and Ground Deicing, SAE Technical Paper 2011-38-0018 or NASA/TM-2012217429, June 2011.

Page 7 of 9 
9. Currie, T. C., Struk, P. M., Tsao, J., Fuleki, D., and Knezevici, D. C. "Fundamental Study of Mixed-Phase Icing with Application to Ice Crystal Accretion in Aircraft Jet Engines," 4th AIAA Atmospheric and Space Environments Conference, AIAA-2012-3035, June 2012.

10. Struk, P. M., Bencic, T., Tsao, J., Fuleki, D., and Knezevici, D. C. "Preparation for Scaling Studies of Ice-Crystal Icing at the NRC Research Altitude Test Facility," 5th AIAA Atmospheric and Space Environments Conference, AIAA-2013-2675 and NASA/TM-2013-216571, 2013.

11. Struk, P. M., Bartkus, T. P., Tsao, J. C., Currie, T., and Fuleki, D. "Ice Accretion Measurements on an Airfoil and Wedge in Mixed-Phase Conditions," SAE 2015 International Conference on Icing of Aircraft, Engines, and Structures, SAE Technical Paper 2015-01-2116, June 2015.

12. Struk, P. M., Tsao, J. C., and Bartkus, T. P., "Plans and Preliminary Results of Fundamental Studies of Ice Crystal Icing Physics in the NASA Propulsion Systems Laboratory," 8th AIAA Atmospheric and Space Environments Conference, AIAA-2016-3738, June 2016.

13. Struk, P. M., Ratvasky, T. P., Bencic, T. J., Van Zante, J. F., King, M. C., Tsao, J. C., and Bartkus, T. P., "An Initial Study of the Fundamentals of Ice Crystal Icing Physics in the NASA Propulsion Systems Laboratory," 9th AIAA Atmospheric and Space Environments Conference, AIAA-2017-4242, June 2017.

14. Veres, J. P., Jorgenson, P. C. E., "Modeling Commercial Turbofan Engine Icing Risk with Ice Crystal Ingestion," 5th AIAA Atmospheric and Space Environments Conference, AIAA- 2013-2679 and NASA/TM-2013-218097.

15. Jorgenson, P. C. E., Veres, J. P., Coennen, R., "Modeling of Commercial Turbofan Engine with Ice Crystal Ingestion; Follow-On," 6th AIAA Atmospheric and Space Environments Conference, AIAA-2014-2899 and NASA/TM-2014-218496.

16. Veres, J.P., Jones, S.M., Jorgenson, P.C.E., "Performance Modeling of Honeywell Turbofan Engine Tested with Ice Crystal Ingestion in the NASA Propulsion System Laboratory," SAE 2015 International Conference on Aircraft and Engine Icing and Ground Deicing, SAE Technical Paper 2015-01-2133.

17. Veres, J.P., Jorgenson P. C. E., Jones, S. M., "Modeling of Highly Instrumented Honeywell Turbofan Engine Tested with Ice Crystal Ingestion in the NASA Propulsion System Laboratory," 8th AIAA Atmospheric and Space Environments Conference, AIAA-2016-3895, June 2016.

18. Veres, J.P., Jorgenson, P.C.E., Jones, S.M., Nili, S., "Modeling of a Turbofan Engine with Ice Crystal Ingestion in the NASA Propulsion Systems Laboratory," ASME IGTI 2017 Turbo Expo, Charlotte, NC, June 26-30, 2017, GT2017-63202.

19. Anderson, D. N., "Manual of Scaling Methods," NASA /CR2004-212875, March 2004.

20. Anderson, D. N. and Tsao, J. C., "Ice Shape Scaling for Aircraft in SLD Conditions," NASA/CR-2008-215302, DOT/FAA/AR07/55, September 2008.

21. Messinger, B.L., "Equilibrium Temperature of an Unheated Icing Surface as a Function of Airspeed," J. Aer-on. Sci., vol. 20 no. 1, January 1953 , pp $29-42$.

22. Griffin, T. A., Lizanich, P., and Dicki, D. J., "PSL Icing Facility Upgrade Overview," 6th AIAA Atmospheric and Space Environments Conference, AIAA-2014-2896, 2014.

23. Dicki, D., Thomas, Q., Oliver, M., Kowalewski, J., Poljak, P., Zimmerle, K., Rosine, B., Rachow, P., Shrewsbury, C., "Propulsion Systems Laboratory Customer Guide Update," 2019 SAE International Conference on Icing of Aircraft, Engines, and Structures, 19ICE-0160, Minneapolis, MN, June 17-21, 2019.

24. Van Zante, J., Ratvasky, T., Bencic, T., Challis, C. and Timko, E., "Update on the NASA Glenn Propulsion Systems Lab Icing and Ice Crystal Cloud Characterization - 2017," $10^{\text {th }}$ AIAA

Atmospheric and Space Environment Conference, AIAA-20183969, June 2018.

25. Flegel, A., Agui, J., King, M., Tsao, J. C. and Chen, R. C., "Ice Crystal Effects on a Hidden Core Turbofan Engine in an Altitude Simulation icing Facility," Oral Presentation, 2019 SAE International Conference on Icing of Aircraft, Engines, and Structures, 19ICE-0137, Minneapolis, MN, June 17-21, 2019.

26. King, M., Flegel, A., Bencic, T., Manin, J., Baumgardner, D., Dischinger, D., Wienkes, L. and Wilson, B. "Particle Size Measurements from the 2018 Honeywell Uncertified Research Engine Test in the NASA Propulsion System Laboratory," 2019 SAE International Conference on Icing of Aircraft, Engines, and Structures, 19ICE-0147, Minneapolis, MN, June 17-21, 2019.

27. Veres, J. P., Jorgenson, P. C. E., "Prediction and Analysis of Ice Accretion in a Research Turbofan Engine With Ice Crystal Cloud Ingestion at Simulated Altitudes," NASA/TM-2017219724 (availability restricted to U.S. government and NASA contractors)

28. Jorgenson, P. C. E., Veres, J. P., Bommireddy, S. R., Nili, S., "Analysis of the Honeywell Uncertified Research Engine (HURE) with Ice Crystal Cloud Ingestion at Simulated Altitudes (Public Version),"NASA/TM-2018-220023.

29. Rigby, D. L., Wright, W. B., Flegel, A. and King, M., "Simulation of Ice Particle Breakup and Ingestion into the Honeywell Uncertified Research Engine (HURE)," 2019 SAE International Conference on Icing of Aircraft, Engines, and Structures, 19ICE-0159, Minneapolis, MN, June 17-21, 2019.

\section{Contact Information}

Jen-Ching (Paul) Tsao, Principal Research Scientist

Work phone: (216) 433-2411

E-mail: jenching.tsao-1@nasa.gov

Affiliation: Ohio Aerospace Institute

\section{Acknowledgments}

This work was supported under the NASA Advanced Air Vehicles Program, Advanced Air Transport Technology Project and the Aeronautics and Evaluation Test Capability Project. The first author was supported under a NASA ARTS contract. The author wishes to acknowledge the financial support for this work. The author also wishes to acknowledge the special help and guidance received from Mr. Joe Veres and Dr. Phil Jorgenson for providing COMDESMELT analysis results and the contributions from the rest of the Engine Icing Research team for this work. The author would like to thank the entire PSL staff for their dedication and support of this test. The author also wishes to thank the Honeywell team for their contributions during the engine test.

\section{Definitions/Abbreviations/Subscripts}

$b^{*}$

$c^{*}$

$E G V$

$\boldsymbol{h}_{c}$ modified relative heat factor

specific ratio of ice particle kinetic heating to latent heat absorbed from melting

exit guide vane

convective heat-transfer coefficient $\left[\mathrm{cal} / \mathrm{s} \mathrm{m}^{2} \mathrm{~K}\right.$ ] 
$h_{G}$

IGV

IWAR

IWC

LWC

MMD

$M R$

MVD

$\boldsymbol{M}_{\infty}$

$\dot{m}_{i m p}$

mo

N1

N2

no

$p$

$p_{v, w \infty}$

$p_{v, w s}$

RH

SH gas-phase mass-transfer coefficient $\left[\mathrm{g} / \mathrm{s} \mathrm{m}^{2}\right]$

inlet guide vane

normalized $\mathrm{IWC}=\mathrm{IWC} / \rho_{\mathrm{a}}$

ice water content $\left[\mathrm{g} / \mathrm{m}^{3}\right]$

liquid water content of melt $\left[\mathrm{g} / \mathrm{m}^{3}\right]$

ice crystal median mass diameter [ $\mu \mathrm{m}]$

ice crystal melt ratio, $=\mathrm{LWC}_{\mathrm{t}} / \mathrm{IWC}_{\mathrm{i}}$

water drop median volumetric

diameter $[\mu \mathrm{m}]$

local Mach number

mass flux of ice/liquid-water particle impinged per unit time, $\mathrm{lbm} / \mathrm{ft}^{2} \mathrm{~s}$

melting fraction at stagnation region

fan speed [rpm]

core speed $[\mathrm{rpm}]$

freezing fraction at stagnation region

air static pressure $\left[\mathrm{N} / \mathrm{m}^{2}\right]$

saturation water vapor pressure in ambient $\left[\mathrm{N} / \mathrm{m}^{2}\right]$

saturation water vapor pressure at icing interface $\left[\mathrm{N} / \mathrm{m}^{2}\right]$

relative humidity

specific humidity $[\mathrm{g} / \mathrm{kg}]$
$T_{s}$

$T_{w b}$

$T_{\infty}$

$T W C$

V

$V W C_{\text {gain }}$

W

$\Lambda_{f}$

$\Lambda$ v

$\rho a$

Subscripts:

cor

ff

i

pl

$\mathrm{t}$

0

$\infty$ icing surface temperature $\left[{ }^{\circ} \mathrm{C}\right]$

wet bulb temperature $\left[\left[{ }^{\circ} \mathrm{C}\right]\right.$

air static temperature $\left[{ }^{\circ} \mathrm{C}\right]$

total water content $\left[\mathrm{g} / \mathrm{m}^{3}\right]$

air velocity $[\mathrm{kt}]$

vapor water content gained $=$ $V W C_{t}-V W C_{i}\left[\mathrm{~g} / \mathrm{m}^{3}\right]$

fan face mass flow rate $[\mathrm{lbm} / \mathrm{s}]$

latent heat of fusion $[\mathrm{cal} / \mathrm{g}]$

latent heat of evaporation [cal/g]

air density $\left[\mathrm{kg} / \mathrm{m}^{3}\right]$

corrected

fan face

inlet, initial or cloud off

in the plenum

target, terminal or cloud on

at the surface

stagnation or total value

local static or ambient condition 